CADERNOS GESTÃo PÚBLICA E CIDADANIA

\title{
INFORMAÇÃO, TRANSPARÊNCIA E CIDADANIA - O CONTROLE DA EXECUÇÃO ORÇAMENTÁRIA PELO CIDADÃo
}

Peter Spink 


\section{O Autor}

\section{Peter K. Spink}

Ph.D em Psicologia Organizacional pela London University. Professor Titular da EASP da Fundação Getúlio Vargas de São Paulo. Implantou e coordena o Programa Gestão Pública e Cidadania desde 1995.

* Este trabalho foi apresentado no I Congresso Brasileiro de Controle Social do Orçamento Público em Belo Horizonte de 15 a 17 Julho de 1999. 


\section{INFORMAÇÃO, TRANSPARÊNCIA E CIDADANIA - O CONTROLE DA EXECUÇÃO ORÇAMENTÁRIA PELO CIDADÃO}

Gostaria de agradecer, em nome da equipe do Programa Gestão Pública e Cidadania, o convite para participar desta mesa e deste evento que é muito importante para todos nós que nos preocupamos com o dia a dia da ação pública. No caso do programa, o foco de nossas observações são os governos subnacionais, e durante os últimos quatro anos temos recebido informações sobre mais de 2.500 projetos e atividades em todas as esferas da ação pública - incluindo as de informação e finanças - que buscam inovar não somente em relação aos serviços prestados, mas também, na construção ativa da cidadania. É a partir destas observações e também de algumas discussões específicas com colegas em outros países que pretendo desenvolver a minha contribuição.

Quero começar deixando muito claro a minha posição sobre o engajamento dos cidadãos no processo de orçamento público.

1. sem isso não há um orçamento público - há, ao contrário, um orçamento privado que serve grupos de interesse específicos

2. por causa disso, devemos priorizar e focalizar o processo de orçamento como o terreno privilegiado de disputa para a concretização da vida democrática e da inclusão social

3. em conseqüência, deveríamos dizer - com relação aos meios e instrumentos quanto mais melhor, nas diversas direções possíveis e com as mais variadas técnicas.

Vamos por partes - primeiro o orçamento não é um instrumento de gestão financeira. Esta visão reduzida e até falsa, tem contribuído para uma perspectiva onde a discussão técnica sobre orçamento e finanças tem transformado o cenário do gasto público numa caixa preta, administrada, no interesse público, por bem intencionados sacerdotes com doutorados em economia e finanças públicas.

Orçamento é, sim, um instrumento de gestão: de planejamento, de monitoramento e de controle (no duplo sentido de que o previsto a ser feito serve também para definir como vai ser feito e quando e, também, o que não vai ser feito). Enquanto instrumento de planejamento, os orçamentos públicos refletem não somente estratégias e teorias sobre ação, mas também as relações de poder explícita e implicitamente presentes na disputa para os espaços e as prioridades. 
O problema com a visão falsa sobre o orçamento público enquanto ação financeira, essencialmente técnica e burocrática, é que ela acaba - sem perceber - apoiando a doce ilusão de que são os macro temas e as grandes questões que são importantes porque é lá que reside o poder. O resultado é que boa parte da mobilização social tem se orientado para o terreno das políticas públicas - as grandes orientações que, supostamente, fornecem os rumos das múltiplas ações das organizações, agências e repartições públicas. O que é erroneamente concebido como a máquina pública.

Erroneamente e também ilusório, porque não são máquinas que podem ser orientadas e deixadas para seguir instruções. São ligações e arranjos complexos entre pessoas e tarefas, onde há múltiplas opções para ação, e múltiplas maneiras de concretizar políticas e planos. Nesta complexidade, exige-se não somente a aderência a regras e procedimentos, mas também o uso do bom senso. Entretanto, bom senso pode ser senso, mais o bom depende da perspectiva intersubjetiva de sua produção - de conversas entre profissionais tendo como referência posições de profissão, de categoria, de grupo político ou de teorias práticas sobre ação social.

Pense por um momento a respeito de um servidor que trabalha diretamente em contato com os cidadãos. Vamos imaginar uma professora de escola pública decidindo se vai deixar um aluno difícil passar de ano por causa de razões sociais e os apelos da mãe do aluno, ou se evita dar aquele meio ponto e faz o aluno repetir. Ou um policial refletindo sobre dar uma bronca e ter uma discussão séria com alguém, ou levá-lo à delegacia. E assim vai.... Há muitas pequenas decisões deste tipo sendo tomadas diariamente, milhares de pequenas ações que abrem ou fecham possibilidades e esperanças. É claro que uma política bem formulada ajuda, mas quantas são de fato bem e claramente formuladas?

Temos, portanto, de reconhecer que entre a política e o resultado há um espaço bastante denso e opaco, não necessariamente por razões negativas; simplesmente a conseqüência de tantas ligações diferentes entre pessoas e tarefas e seus múltiplos mecanismos de coordenação e comando. É aqui que reside também o lado nefasto da opacidade - o uso da falta de transparência para fins próprios; seja para o executivismo do cacique ou caudilho populista para o qual o ofício público é visto imperiosamente, seja para as ações explícitas de privilégio e de enriquecimento próprio daqueles que vêem o terreno público como propriedade particular. 
Surge então a pergunta: como influenciar este espaço de ação amplo que transforma as políticas em ações concretas? Como monitorar e apontar antecipadamente a ausência destas ações, ou identificar seu desvirtuamento a favor dos novos setores industriais que emergem e se alimentam na opacidade e complexidade pública: a indústria da seca, a indústria do lixo, a indústria da merenda e a indústria da pobreza?

A avaliação mais formal das políticas públicas, especialmente de seu impacto, tende a ser uma atividade feita após as ações previstas e, infelizmente em muitos casos nem isso acontece ou, quando feita, ocorre de forma simplista. Também, o acompanhamento de cada funcionário e cada decisão seria fisicamente impossível e socialmente injusto, porque seria a negação da possibilidade ou da confiança de um agir público.

Entre estes, não tão macro quanto a política e não tão micro quanto a ação individual, há um espaço de médio alcance que começa a se delinear. Formado por mecanismos de cogestão de obras e serviços entre organizações da comunidade e do Estado, por conselhos e comitês setoriais que coordenam e acompanham ações de maneira conjunta e, permeando este espaço como um todo, o orçamento.

Em agosto de 1998, organizamos em São Paulo junto com a Universidade do Texas Austin e com o apoio da Fundação Ford, um pequeno seminário em que pesquisadores e ativistas no acompanhamento dos orçamentos públicos em diversos países trocaram experiências. Todos foram unânimes tanto sobre a importância de se batalhar para tornar os processos e os conteúdos orçamentários mais públicos, quanto sobre a falta de atenção que tem sido dada a esta questão enquanto fenômeno político, decisório, operacional e organizacional; o terreno de médio alcance onde é construída a ação pública.

Haviam pessoas da Argentina, Chile, México, Brasil e dos Estados Unidos, e aprendemos bastante juntos, mas também percebemos que em todos os países os processos orçamentários se caracterizam pela opacidade e não pela transparência. Vimos também que as experiências brasileiras de engajamento do cidadão na elaboração e execução dos orçamentos públicos subnacionais tem se dado de diversas maneiras, nas cidades que adotam essa prática. Alguns exemplos são ilustrativos da diversidade de estratégias utilizadas,como o uso da informática e da internet; a utilização do muro principal da escola municipal como o lugar de expor o orçamento municipal de educação; a realização consultas em reuniões e assembléias; criando novas estruturas dinâmicas, territorialmente e tematicamente representativas; buscando melhorias e aperfeiçoamentos nos processos de 
orçamento participativo. Essas práticas são vistas por outros como bastante avançadas, que estão abrindo terreno novo na construção de uma democracia ativa. Em alguns países o orçamento nem tramita pelos espaços públicos e, muito menos, pelas assembléias legislativas. Há áreas significativas de orçamento que são privilegio do executivo e tal como aqui também, há todo uma série de artimanhas que permite um jogo de escondeesconde, da passagem subterrânea de uma rubrica ou categoria para uma outra.

De país para país, as formas de organização subnacional variam bastante. Em muitas outras partes da América Latina, não há, por exemplo, municípios como nós conhecemos aqui, com espaços territoriais contíguos, confirmados pela constituição. Nos Estados Unidos, ao contrário do que se pode imaginar, há pelo menos cinco modelos diferentes de administração local, dependendo da constituição estadual, de preferências e de costumes locais. Alguns descendem diretamente da cidadania ativa e da representação direta oriunda das práticas religiosas de dissensão e de congregação comunitária dos peregrinos. Conseqüentemente, você pode encontrar cidades pequenas onde ainda ocorre a reunião da cidade, tal como acontece na Suíça. Há também modelos mais executivos onde o voto para prefeito é separado do voto para conselheiros ou vereadores. Há modelos onde o prefeito nada mais é do que um dos vereadores, escolhido entre eles como líder do conselho municipal e há modelos onde o prefeito ou o conselho contratam o que é chamado de "gerente de cidade" (city manager), como o encarregado ou responsável geral para a gestão dos serviços públicos. Em certos lugares pessoas votam por distrito, e em outros votam de maneira geral - como nós fazemos. Os serviços de educação são normalmente fornecidos por organizações intermunicipais no nível dos condados (não dissimilar aos nossos consórcios intermunicipais temáticos), e saúde e serviços sociais tem também outras estruturas, mas há mesmo assim um número de serviços significativos que são responsabilidade direta do município - polícia, bombeiros, estradas, saneamento, resíduos sólidos, zoneamento, alvarás e proteção ambiental.

Quais as implicações - a não ser por curiosidade - destas diferenças ? Se por um momento suponhamos que os Estados Unidos é um país vagamente democrático como muitos outros - não é uma das sete maravilhas, mas também não é totalmente um desastre ambulante teríamos que refletir que, talvez as discussões que ocorrem no Brasil sobre "se o orçamento participativo enfraquece a câmara dos vereadores"; "se leva a um fortalecimento do executivo"; "se cria um novo modelo de democracia"; "se é possível imaginar subprefeituras, ou plebiscitos" e daí por diante podem ser uma perda de tempo. 
Não é o modelo abstrato e institucional que gera a democracia; ao contrário é a ação coletiva de pessoas que vão buscar formas de agir que ora ajudam ora atrapalham e conseqüentemente são estabilizadas ou alteradas. Neste processo é de se esperar que emergirão práticas diferentes - por que temos que ter um modelo específico, único e hegemônico?

Nos casos brasileiros de orçamento popular de maior envergadura e que datam do final da década de 80 , é nítido o processo de aprendizagem coletiva e de ajuste que tem havido e continuará havendo, como também os caminhos diferentes que foram seguidos e as diferenças entre modelos em uso. Os orçamentos participativos estão criando mecanismos de representação distrital, criando fóruns de negociação dos mais variados tipos e, mais importante, estão levando as pessoas a verem a importância do processo orçamentário não somente na formulação, mas também na execução. Estamos - talvez pela primeira vez construindo e negociando novos tipos de instituições e relações entre o estado local e a sociedade civil, entendendo estas instituições e relações como espaços sociais, ações e práticas feitas artesanalmente, pelas mãos das forças coletivas.

Em colaboração com colegas na Universidade do Texas - Austin, estudamos comparativamente algumas experiências que podem ser caracterizadas, nos Estados Unidos, como inovadoras em relação ao orçamento público local e algumas experiências brasileiras de orçamento participativo (Robert Wilson, Natasha Sugiyama, Gilberto Hashimoto e Peter Spink). Uma das dificuldades significativas no acompanhamento público do orçamento nos Estados Unidos é resultado da fragmentação e sobreposição de responsabilidades de municípios, condados, agências e estados. Quem faz exatamente o que? - especialmente nas grandes áreas urbanas onde todos podem estar presentes.

Duas das três experiências que foram identificadas como sendo inovações importantes estavam ligadas a momentos de crise fiscal. Em Claremont, Califórnia - uma cidade de classe média acadêmica com uma população de 34,000 - uma mescla de crise fiscal e de crítica sobre a falta de democracia nos processos decisórios levou a equipe administrativa e profissional da prefeitura a propor um processo de consulta ampla, usando questionários e reuniões comunitárias, que foi denominado de "Claremont Choices". As bases do debate foram qual o balanço de serviços e impostos, e o que priorizar. Um sucesso inicialmente, o exercício continuou no anos seguintes mas gradativamente perdeu fôlego, passando a focalizar mais as questões de vizinhança e menos a temática fiscal. 
Sacramento com uma população de 388,000 , é a capital da Califórnia e uma cidade bastante heterogênea em termos de classes sociais, oportunidades desiguais de inserção no mercado de trabalho e tensões raciais. De novo, a previsão ou projeção de um déficit grande foi o estímulo, e também neste caso, os esforços foram liderados pelo pessoal administrativo e técnico da prefeitura. O processo, chamado de "Sacramento Decisions" usou uma variedade de técnicas: pesquisas de amostragem, pesquisa por telefone, levantamentos feitos pelos jornais da cidade, oficinas comunitárias e um exercício interessante que simulava o processo de equilíbrio orçamentário incluindo até detalhes como os custos de alocação de um policial numa área ou outra. O processo mobilizou bastante a cidade e sem dúvida ajudou a criar um equilíbrio orçamentário que foi muito mais aceito e respaldado pela comunidade. Muitas prioridades foram fixadas e questões específicas locais também trabalhadas. Entretanto o processo foi visto como algo difícil de repetir por causa do custo.

O terceiro exemplo vem de San Antonio, Texas, uma cidade com uma população de quase 1 milhão de habitantes, bastante diversa em termos socio-econômicos, com uma presença latina forte e uma história de exclusão social e política. Aqui o processo foi totalmente diferente. Um processo de mobilização social e fortalecimento das comunidades pobres e excluídas durante um número de anos, apoiado pelas igrejas e pela Fundação para Áreas Industriais (uma organização independente de apoio à mobilização comunitária), cruzou com uma abertura institucional, fiscal e político criado por uma nova forma de financiamento federal a fundo perdido (conhecido como uma doação em bloco - um block grant). Esta doação foi disponibilizada para investimentos pelas municipalidades em áreas urbanas, mas exigia alguma forma de consulta popular. O município, argüindo que já tinha feito a devida consulta optou por uma série de melhorias, incluindo um campo de golfe. O movimento urbano das pessoas pobres, latinas e excluídas (com o nome de COPS -Comunidade organizadas para serviço público) decidiu brigar. Usando todas as habilidades de pressão possível, colocando candidatos em eleições, forçando o Governo Federal a inspecionar o uso de fundos, exigindo a presença dos oficiais do município em reuniões públicas e muito mais - forçaram a abertura do processo de investimento do município e a priorização de serviços e ações para as áreas mais necessitadas. Na visão da COPS, a comunidade tem que se organizar para pressionar o governo local a assumir suas responsabilidades. Uma comunidade forte gera uma democracia forte. 
Quando se contrasta estas experiências com as experiências brasileiras de orçamentos participativos é possível, respeitando as diferenças, tirar se não conclusões, pelo menos algumas indagações.

Quando o processo se inicia de dentro da prefeitura para fora, em resposta à crise, o resultado sem dúvida é uma ampliação do espaço democrático, mas o problema é um problema político específico (como ter um orçamento equilibrado) e não de inclusão ou de construção de cidadania. Entretanto os métodos de consulta desenvolvidos em Claremont e em Sacramento tem muito a oferecer, na medida em que buscam informar didaticamente não somente sobre as escolhas mas sobre a lógica do orçamento enquanto processo gerencial (em Claremont, por exemplo, a população votou depois para elevar certos impostos). No caso de San Antonio o processo não é de uma política, ou de um equilíbrio orçamentário, mas de acesso a fundos e do direito de determinar onde são direcionados. É um confronto aos modelos existentes de distribuição e uma maneira de forçar sua redistribuição. De certa forma, para o COPS, o jogo é um jogo de soma zero - a distribuição será sempre desigual, a questão é de determinar para quem. O processo nasce na comunidade - e vai de fora para dentro da prefeitura.

E os orçamentos participativos? Nasceram em quase todos os casos dentro da prefeitura, com um boa dose de crise ou pelo menos dificuldade de investimento, entretanto foram capazes de ir além das prioridades técnicas e servir de mecanismo para a inclusão e a construção de cidadania. Por isso que atraem tanta atenção, e com toda razão. Igualmente, o processo de aprendizagem social e coletivo também dos que fazem parte, estimula uma certa independência das comunidades organizadas dentro do processo orçamentário, na medida em que habilidades de organização e consulta são recuperadas e as possibilidades para pressão confirmadas. Mas podemos e devemos perguntar, será que o caso de San Antonio também tem algo especial a ensinar em relação ao fortalecimento da democracia enquanto capacidade de comunidades se fazerem presentes, a necessidade de distância institucional entre atores diferentes, e a importância da independência em relação à prefeitura?

Me permito mais um exemplo, desta vez da Bolívia, que somente nove anos atrás, fixou a sua base de organização municipal com claras responsabilidades territoriais. Junto com a legislação de descentralização veio a lei de participação popular que, entre outros elementos, criou um mecanismo de fiscalização popular de grande impacto potencial. Sem mecanismos estabelecidos de transferência fiscal do nacional para o município, o governo 
adotou o seguinte procedimento: $20 \%$ dos recursos do tesouro nacional seriam divididos per capita e transferidos para os municípios de acordo com a sua população. Foi chamado de fundo de co-participação.

Eu sei o que os teóricos de transferência vão dizer - espere, não é tão simples assim - mas foi uma estratégia que funcionou. Pelo menos não precisavam passar anos discutindo as filigranas de porcentagens e mecanismos de compensação e, mais importante, conseguiram criar um mecanismo que era facilmente entendido (alias o cálculo de receita municipal per capita é um exercício que recomendo).

A parte que nos interessa mais especificamente é a que seguiu. Em cada município a lei criou o que é chamado "comitê de vigilância" como órgão separado à estrutura municipal de prefeito, câmara e demais oficiais. Os comitês de vigilância foram formados por cidadãos eleitos por organizações sociais e populares com uma representação territorial. Para ser registrado como organização territorial de base, o termo usado, estas organizações tiveram que demonstrar que já existiam há pelo menos cinco anos antes do ato de registro. Em 1996, algo em torno de 13,000 organizações populares das comunidades e dos trabalhadores rurais, das associações de moradores e dos povos indígenas tinham se registrado. Estes, município eram responsáveis na época pela eleição dos 1600 membros dos 311 comitês municipais de vigilância existentes.

A função do comitê de vigilância é de acompanhar o uso dos recursos do fundo de coparticipação e demais fundos municipais nos planos desenvolvidos e nos projetos de investimento - para garantir que aquilo que é para ser realizado é realmente feito. Nada mais e nada menos do que o monitoramento da execução orçamentária. O comitê tem o direito de denúncia ao nível departamental - o próximo nível - que pode congelar a transferência do fundo de co-participacao. Em cidades grandes, há agora comitês por zona ou área regional, em lugares de fácil acesso à população: por exemplo no mercado local. Como não podia deixar de ser, porque somos todos antes de mais nada seres sociais com os nossos costumes e práticas, a introdução da lei de participação social levou tanto a avanços como também a processos de coerção e de influência pelas oligarquias locais e também por algumas das estruturas indígenas mais autoritárias. Entretanto, serviu como uma lição em grande escala sobre a importância de acompanhar o que é para ser feito, e de garantir acesso aos cidadãos a este espaço de médio alcance. 
A implantação dos "Comitês de vigilância" também demonstrou a importância do reconhecimento das organizações populares territoriais existentes, cujos representantes eleitos levaram consigo suas tradições e preocupações para com a propriedade comunitária. Durante os primeiros anos, aparecia de vez em quando no noticiário boliviano que a polícia junto com membros respeitados do governo departamental(o próximo nível) teve que correr para este ou aquele povoado, para evitar que o comitê de vigilância enforcasse o prefeito no posto de luz em frente da prefeitura. De fato as notícias eram exageradas, mas houveram tumultos e denúncias constantes sobre a má aplicação dos recursos; sem dúvida os comitês de vigilância são diferentes de nossos tribunais de contas.

Fazendo este exercício de prestar atenção aos cidadãos e comunidades, suas democracias e seus orçamentos, em países diferentes, percebemos avanços e também dilemas. Avanços no reconhecimento de que temos mesmo que pular fora do debate interminável sobre a determinação das políticas públicas, e reconhecer que se tratam de processos sociopolíticos que produzem e reproduzem desigualdades que podem ser identificados, influenciados e confrontados no espaço de médio alcance que é da formulação e execução orçamentário.

Avanços também no reconhecimento dos múltiplos mecanismos disponíveis desde os mais engajados que criam novos espaços, instituições e mecanismos até o aparentemente simples, mas tremendamente importante mecanismo de publicação e tradução de orçamentos, decodificando e demonstrando o que acontece. No Chile, por exemplo, se você quer saber o valor do orçamento militar para a compra de armamentos, você precisa saber olhar uma linha específica do balanço anual da Companhia Estatal de Cobre. Alguns de nossos governos estaduais estão colocando seus programas de acompanhamento de execução orçamentário nas assembléias legislativas e em terminais de acesso livre - cabe agora aprender a decodificá-los.

Há também muitos outros meios de trabalhar com informação e acesso. Nos quatro anos do Programa de Gestão Publica e Cidadania temos visto toda uma variedade de soluções simples e eficazes na produção de serviços públicos com dignidade e respeito, onde a informação é compartilhada e as dificuldades são discutidas francamente; entre estas estão as questões orçamentárias de prioridade e de escolha.

Há também dilemas, porque orçamento não é - nem majoritariamente - investimento, mas as despesas do dia a dia, os salários de servidores e os custos dos diferentes serviços 
públicos. Aprendemos entretanto, com Claremont e Sacramento, como entrar na discussão sobre o direcionamento e a localização destes serviços. Há também o dilema que vem do processo de construção histórico em si, de ter que escolher opções que não são perfeitas porque ninguém saberia dizer o que é perfeito. Aqui também é importante lembrar o gradativo processo de construção, alteração e inovação representado por cidades como Porto Alegre e Ipatinga. Mas também aprendemos com San Antonio e com os comitês de vigilância na Bolívia, que às vezes para fazer o omelete democrático é necessário quebrar ovos. 